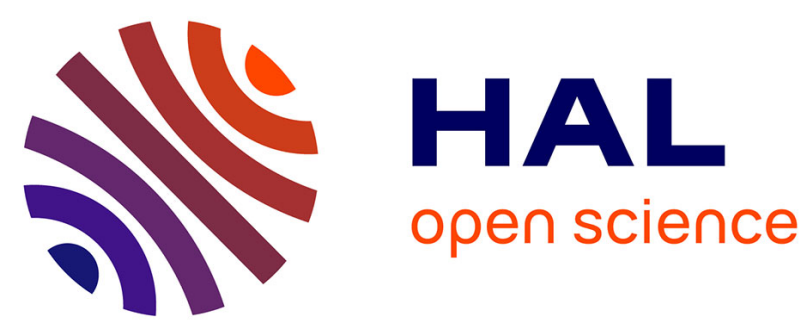

\title{
Assessing interoperability requirements in networked enterprises: A model-based system engineering approach
}

Gabriel S S Leal, Wided Guédria, Hervé Panetto

\section{To cite this version:}

Gabriel S S Leal, Wided Guédria, Hervé Panetto. Assessing interoperability requirements in networked enterprises: A model-based system engineering approach. INSIGHT - International Council on Systems Engineering (INCOSE), 2017, 20 (4), pp.15-18. 10.1002/inst.12174 . hal-01673068

\section{HAL Id: hal-01673068 \\ https://hal.science/hal-01673068}

Submitted on 28 Dec 2017

HAL is a multi-disciplinary open access archive for the deposit and dissemination of scientific research documents, whether they are published or not. The documents may come from teaching and research institutions in France or abroad, or from public or private research centers.
L'archive ouverte pluridisciplinaire HAL, est destinée au dépôt et à la diffusion de documents scientifiques de niveau recherche, publiés ou non, émanant des établissements d'enseignement et de recherche français ou étrangers, des laboratoires publics ou privés. 


\section{Assessing interoperability requirements in networked enterprises: A model-based system engineering approach}

Gabriel Leal (gabriel.leal@list.lu), Wided Guédria (wided.guédria@ list.lu) and Hervé Panetto (herve.panetto@incose.org)

In the fast-changing environment that we are living in, enterprises need to work collaboratively with other companies to remain competitive. The businesses that are progressively collaborating with others are becoming the so-called Networked Enterprise (NE) (Jagdev et al. 2001), (Camarinha-Matos and Afsarmanesh 2005). In this context, communication and collaboration problems can impact the performance and the outcomes of the network drastically. Hence, to avoid these kinds of problems, enterprises should share their core competencies and improve their interoperability (IEEE 1990) i.e. the ability of systems to exchange and share information and functionalities and use them in a meaningful manner. The interoperability per se happens when two enterprise systems (humans, software, etc.) belonging to the members of the network, successfully interoperate with each other. Thus, the ability to interoperate is a crucial requirement to be verified when enterprises are creating or maintaining collaborative relationships.

For improving their interoperability, companies could benefit from the use of interoperability assessment approaches. One of the first steps of this kind of assessment is the analysis of the system's AS-IS situation considering the different areas of interoperability (ISO 2015) and their requirements. However, based on the comparative studies (Ford 2007), (Rezaei et al. 2014), we identified that the majority of existing assessment approaches are dealing with a particular area of interoperability. Hence, we raise the following question: "How can we assess the interoperability, when dealing with different areas of interoperability, in the NE context? " For answering this question, we argue that the use of a holistic assessment approach based on interoperability requirements dependencies could be fit. Hence, we consider that knowing the requirements' dependencies among the different areas, one may identify the potential positive impacts if a requirement is fulfilled or negative impacts if not.

Therefore, this article aims at identifying and classifying the interoperability requirements and their dependencies. To do so, we propose to apply a model-based system engineering (MBSE) approach to designing a NE as a System of Systems (SoS). The MBSE is the formalised application of modelling to support system requirements, design, analysis, verification and validation activities (INCOSE 2007). This allows us to identify the SoS characteristics that can be associated with the NE concept and that can be "translated" into requirements. It worth noting that the contribution of this article is part of an ongoing research work for developing an interoperability assessment approach supported by a semi-automated tool. The identified requirements will be the inputs of the aforementioned approach.

Thus, in a preliminary work (Leal et al. 2016), we hypothesise that a NE can be seen as a System-of-Systems composed of at least two autonomous systems (enterprises) that collaborate during a period of time to reach a shared objective, where interoperability requirements should be met for ensuring the network functioning. This hypothesis is raised based on the SoS definition proposed by Krygiel (1999): a SoS is an interoperating collection of component systems that produce results unachievable by the particular systems alone (Krygiel 1999), where component systems are themselves typically heterogeneous, interdisciplinary and distributed systems (INCOSE 2011).

In more recent years, Morel et al. (2007) focus on the interoperation complexity between existing enterprises and components systems architected as a SoS-like. The authors propose a paradigm for system-of-systems design, where a SoS is a loosely coupled system, which is the result of the aggregation of other loosely coupled systems. Such systems are 
engineered, based on the requirements provided by the client (i.e. the entity that requested the system). Further, the Ontology for Enterprise Interoperability (OoEI), (Naudet et al. 2010) was proposed to formally describe the main components of a system, regarding the interoperability domain. In (Guédria and Naudet 2014) the OoEI was enriched with "Enterprise as a System" concepts for identifying more precisely the relations between the interoperability and the enterprise systems. Based on the studied SoS concepts, we enriched the proposed model in (Leal et al. 2016). An overview of the mentioned model is illustrated in Figure 1.

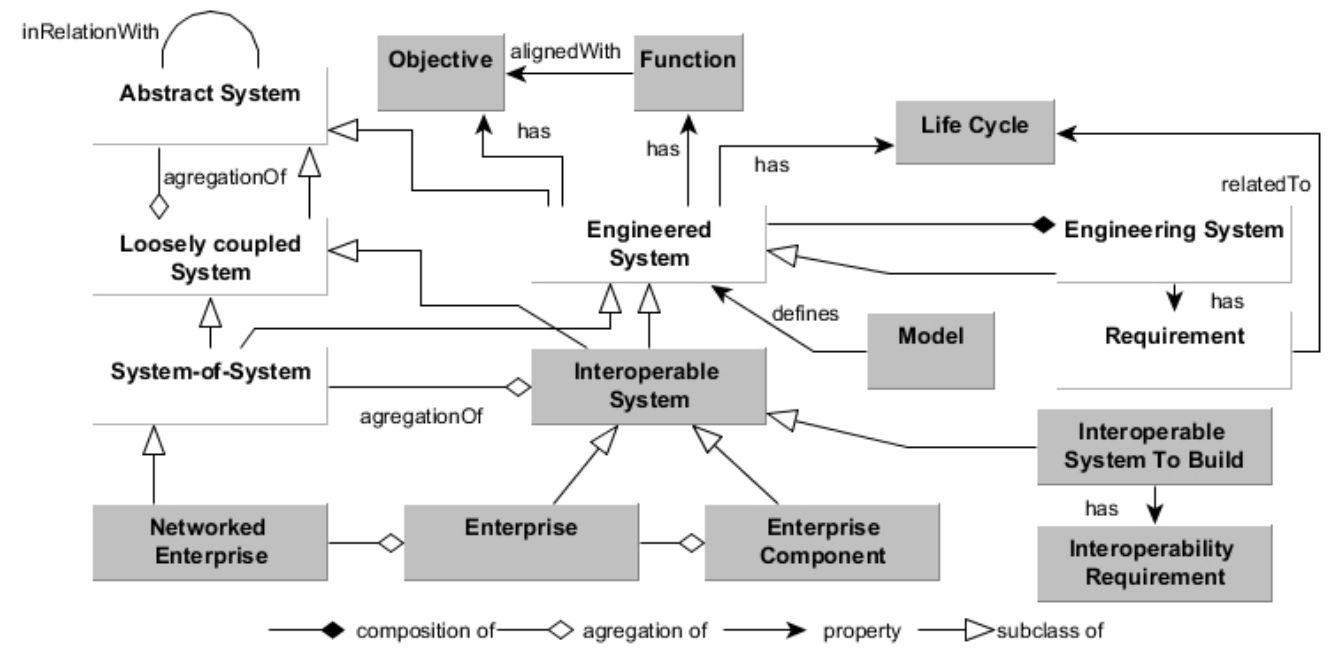

Figure 1. An overview of the Networked Enterprise Meta-Model. The white concepts depict the concepts from SoS related works, and the grey ones represent the concepts from the (Leal et al. 2016).

In Figure 1, the Abstract System concept is introduced to represent the generic form of a system. Further, a Networked Enterprise is seen as a System-of-Systems which is an aggregation of Enterprises, which are themselves aggregation of Enterprise Components. Moreover, we observe that System-of-System, Interoperable System, Enterprises, Enterprise Components and systems to be built (i.e. Engineering Systems and Interoperable System To Build) are subclasses of the Engineered System concept. An Engineered System has a Model defining it. An Engineered System has also a Life Cycle which goes from its creation to its decomposition, undergoing through operation and transformations. It is important to note that systems belonging to a System-of-Systems have different life cycles (INCOSE 2011). Each system has a Function, which in the enterprise context is a set of business activities for achieving Objectives. For realising these functions, a set of Requirements, including Interoperability Requirements must be satisfied. We argue that such requirements can be associated with SoS characteristics and the areas of interoperability.

Regarding the SoS characteristics, Auzelle (2009) summarised six characteristics that can be used in the NE context, which are: the autonomy, belonging, connectivity, diversity, emergence and evolution. The OoEI also pointed out characteristics of an interoperable system that are: stability, openness, and adaptability. Thus, correlating these characteristics to the NE concept, we have the following: (i) The network is an open system where its members are capable of interacting with the network's environment; (ii) The network systems have autonomy i.e. the capability of the enterprises to fulfil their objectives without depending on the other network's systems; (iii) The enterprises have the sense of belonging i.e. the choice to be part of the network, on a cost/benefits basis, for fulfilling their and the network's objectives; (iv) The companies are connected namely the capability of systems to connect with other systems through their interfaces, despite their differences; (v) The network supports the diversity of systems, thus providing a variety of functionalities; (vi) The network has the sense of emergence i.e. the capacity to quickly detect and destroy unintended behaviours; (vii) The 
network supports evolution, in other words, the capability of SoS to adapt themselves to environment changes for ensuring their missions and objectives. Finally, (viii) a network has stability i.e. the capability to remain stable despite any change.

Regarding the areas of interoperability, they are classified according to the interoperability aspects (Conceptual, Organisational and Technical) (ISO 2011), (European Commission 2017) and interoperability concerns (business, process, service and data) (ISO 2011). Based on this classification, we investigated the different existing interoperability assessment approaches and the used evaluation criteria (which can be seen as requirements). Among the studied approaches, the Maturity Model for Enterprise Interoperability (MMEI) (ISO 2015) is the only one explicitly organising and describing the evaluation criteria according to the areas of interoperability. Thus, for now, we are considering mainly the 48 requirements from MMEI.

The next steps are (i) the categorization of the requirements using the SoS characteristics and (ii) their formalisation. The formalisation is done to avoid misinterpretation and to serve as inputs for automated verification techniques. To do so, we apply the formalisation process proposed by Peres et al. (2012). Formalising the requirements, we identify the same atomic requirements that are used by different formulas. Therefore, combining the enterprise systems relations and the requirements similarities, we can define the dependencies of the interoperability requirements. Figure 2(a) shows the formalised requirement DT1. This requirement is related to the connectivity characteristic, and it refers to the data concern and the technical aspect. Figure 2(b) illustrates the same requirement and its interdependencies. The DC1.12 requirement in Figure 2(b) belongs to the Data-Conceptual area of interoperability, and the BT1 belongs to the Business-Technical area.

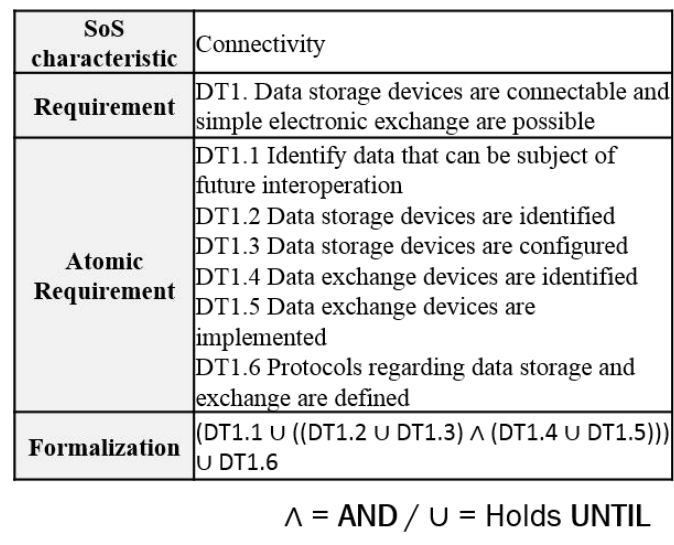

(a)

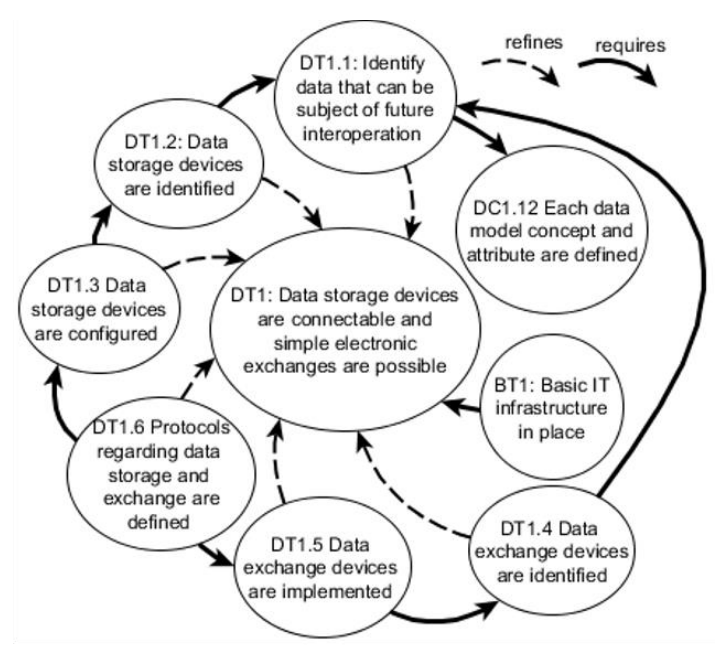

(b)

Figure 2. (a) Example of a formalised requirement. (b) Example of requirement dependencies.

DT1 aims at making different devices connectable for allowing data exchange. In order to fulfil this requirement, a set of atomic requirements should be met first. For example, when a requirement " $\mathrm{A}$ " refines a requirement " $\mathrm{B}$ ", it means that the requirement " $\mathrm{A}$ " is an atomic requirement of "B". Otherwise, requirements may only require another without being an atomic requirement, or may not have any dependency.

As a conclusion, the presented research work depicts the interoperability as a crucial requirement in the NE context. Hence, we argue that the interoperability assessment is relevant for verifying such requirements and for identifying potential impacts that may hinder the network functioning. Such assessment is also relevant for proposing improvements for reducing negative impacts caused by the non-fulfilment of requirements. Moreover, it was 
proposed to represent a network of enterprises as a SoS. It aimed at identifying characteristics of a SoS that are suitable for representing interoperability requirements related to a NE. Knowledge extracted from existing assessment approaches were also used for the identification of requirements. Once the requirements were identified, we formalised them for determining their interdependencies. As future work, we intend, first, to finalise the formalisation of interoperability requirement and their interdependencies. Then, the formalised requirements will be considered as inputs for the assessment tool.

\section{References}

Auzelle, J.-P. 2009. "Proposal a product-centred multi-level model for information system in enterprise". PhD Thesis, University of Nancy (France) (in French)

Camarinha-Matos, L.M. and Afsarmanesh, H., 2005. "Collaborative networks: a new scientific discipline". Journal of intelligent manufacturing 16(4-5), pp.439-452.

European Commission. 2017. European Interoperability Framework - Implementation Strategy. Annex of to the communication from the commission to the European parliament, the council, the European economic and social committee and the committee of the regions.

Ford, T.C., Colombi, J.M., Graham, S.R. and Jacques, D.R., 2007. "Survey on Interoperability Measurement", Paper presented at the $12^{\text {th }}$ International Command and Control Research and Technology Symposium, Newport, 19-21 June.

Guédria, W., Naudet, Y. 2014. Extending the Ontology of Enterprise Interoperability (OoEI) Using Enterprise-as-System Concepts. In: Mertins K., Bénaben F., Poler R., Bourrières JP. (eds) Enterprise Interoperability VI. Proceedings of the I-ESA Conferences, vol 7. Springer, Cham

IEEE (Institute of Electrical and Electronics Engineers). 1990. IEEE Standard Computer Dictionary: A Compilation of IEEE Standard Computer Glossaries.

INCOSE (International Council on Systems Engineering) Technical Operations. 2007. Systems Engineering Vision 2020, version 2.03. Seattle.

INCOSE (International Council on Systems Engineering), 2011. Systems engineering handbook: A guide for system life cycle processes and activities.

ISO (International Organization for Standardization). 2011. ISO 11354-1 2011. Advanced automation technologies and their applications - Part 1: Framework for enterprise interoperability. International Organization for Standardization.

ISO (International Organization for Standardization). 2015. ISO 11354-2 2015. Advanced automation technologies and their applications - Requirements for establishing manufacturing enterprise process interoperability - Part 2: Maturity model for assessing enterprise interoperability

Jagdev, H.S. and Thoben, K.D., 2001. "Anatomy of enterprise collaborations". Production planning \& control 12(5), pp.437-451.

Krygiel, A. J. 1999. Behind the Wizard's Curtain: An Integration Environment for a System of Systems. Washington DC, Office of the Assistant Secretary of Defense.

Leal, G., Guédria, W., Panetto, H. and Proper, E., 2016, June. "Towards a Meta-Model for Networked Enterprise". Paper presented at the 21st international conference on exploring modelling methods for systems analysis and design, Ljubljana, Slovenia, 13-14 June.

Morel, G., H. Panetto, F. Mayer, and J. P. Auzelle. 2007. "System of enterprise-systems integration issues: An engineering perspective". Paper presented at the IFAC Conference on Cost Effective Automation in Networked Product Development and Manufacturing. Monterrey, Mexico, October.

Naudet, Y., Latour, T., Guedria, W., Chen, D. 2010. "Towards a systemic formalisation of interoperability". Computers in Industry 61 (2), pp. 176-185.

Peres, F., Yang, J. and Ghazel, M. 2012. "A formal framework for the formalization of informal requirements". International Journal of Soft Computing and Software Engineering, 2(8), 14-27

Rezaei, R., Chiew, T.K., Lee, S.P. and Aliee, Z.S., 2014. "Interoperability evaluation models: A systematic review". Computers in Industry 65(1), pp.1-23. 